\title{
Inhalt
}

\author{
Abkürzungen - $\mathrm{V}$
}

Dank - VII

Jürgen Dinkel, Steffen Fiebrig, Frank Reichherzer

Zur Historisierung globaler Beziehungen in der zweiten Hälfte des 20. Jahrhunderts: Eine Einleitung - 1

Martin Deuerlein

Inter-Dependenz: Nord-Süd-Beziehungen

und die Auseinandersetzung um die Deutung der Welt -21

Daniel Maul

Von „technischer Hilfe“ zu „basic needs":

Die ILO als Entwicklungsagentur im Nord-Süd-Konflikt -45

Andreas Weiß

Auf der Suche nach dem Süden: Die Europäischen Gemeinschaften und ihr Blick nach Süden in den 1970er und 1980er Jahren — 65

Andreas Hilger

Die globale Ordnung: Sowjetische Entwürfe und indische Alternativen in den 1950er und 1960er Jahren — 85

Stella Krepp

Weder Norden noch Süden: Lateinamerika, Entwicklungsdebatten und die „Dekolonisierungskluft“, 1948-1973_109

Steffen Fiebrig

Unequal exchange? Post-koloniale Wirtschaftsordnung, Handelsliberalisierung und die UNCTAD — 135

Michel Christian

Der Nord-Süd-Konflikt und die „neue internationale Arbeitsteilung“ in den 1970er Jahren: UNIDO, UNCTAD und die Vorgeschichte unserer „Globalisierung“—-171 
$\mathbf{X}-$ Inhalt

Jonas Kreienbaum

Lusaka 1970: Die ökonomische Refokussierung der Bündnisfreien auf ihrem dritten Gipfeltreffen — 195

Dmitri van den Bersselaar

UAC between developmentalists and anti-revolutionaries:

a multinational enterprise makes sense of post-independence Africa -209

Daniel Stahl

„The waste of the arms race must be apparent to all the world“:

Zum Verhältnis von Entwicklungspolitik und Abrüstung im Zeitalter der Détente — 241

Michael Homberg

Von Sendern und Empfängern: Der Nord-Süd-Dialog und die Debatte

um eine Neue Weltinformations- und Kommunikationsordnung _ 263

\section{Sarah Stein}

Die globalpolitische Selbstverortung frankophoner afrikanischer Filmschaffender in den 1960er und 1970er Jahren: Oder warum afrikanische Filmschaffende (lange) nicht vom globalen Norden sprachen — 299

Katja Naumann

Globale Partizipation und universalistisches Wissen: Der Umgang mit der Dekolonialisierung in den sozialwissenschaftlichen Foren der UNESCO -323

Sönke Kunkel

Globales Umweltwissen, Naturgefahren und Wissenschaftsdiplomatie:

Katastrophenhilfe in den Nord-Süd-Beziehungen — 357

Andrea Rehling

Global Commons: Die Figur des „gemeinsamen Erbes der Menschheit“ in den Nord-Süd-Beziehungen — 379

Johanna Sackel

Solidarität vs. Ressourcensouveränität? Die dritte Seerechtskonferenz als Herausforderung für die Süd-Süd-Beziehungen - 405 
Rüdiger Graf

Der Konflikt, der nicht stattfand: Ressourcen, Interdependenz, Sicherheit und die Erwartung des Nord-Süd-Konflikts in den 1970er Jahren — 423

Autor*innen -447

Index - 451 
